\title{
PENERAPAN NILAI KEROHANIAN ISLAM DALAM PERANCANGAN KERJAYA PELAJAR TVET
} Embedding Islamic Spiritual Values in TVET Students ' Career Planning

\author{
${ }^{*}$ AHMAD ROSLI MOHD NOR \\ ${ }^{2}$ MOHAMMAD FAHMI ABDUL HAMID \\ ${ }^{3}$ KHAIRUL AIZAL BIN OSMAN \\ 1,2 Academy of Islamic Contemporary Studies, Universiti Teknologi Mara, \\ Cawangan Melaka, Melaka, Malaysia \\ ${ }^{3}$ Kolej Komuniti Masjid Tanah, Melaka, Malaysia \\ "ahmadrosli@uitm.edu.my \\ Tarikh dihantar: 30 Ogos 2021 / Tarikh diterima: 7 Disember 2021
}

\begin{abstract}
Abstrak Kerjaya merupakan satu agenda penting dalam Islam dalam merealisasikan konsep dunia sebagai jambatan ke akhirat. Kerjaya yang baik perlu dirancang bagi memastikannya kongruen, halal dan menepati kehendak Islam walaupun dalam bidang teknikal yang penuh dengan amali dan kerja tangan. Penerapan nilai kerohanian Islam merupakan perkara yang perlu ada dalam perancangan kerjaya bagi memastikan pelan perancangan menepati kehendak syariat Islam. Justeru, kajian ini telah dilakukan untuk meneroka penerapan nilai kerohanian dalam perancangan kerjaya pelajar Technical and Vocational Education Training (TVET). Kajian berbentuk kualitatif ini menggunakan Focus Group Discussion (FGD) sebagai kaedah kutipan data. Peserta kajian terdiri daripada 12 orang lulusan kolej komuniti dan politeknik telah berjaya dalam kerjaya yang digabungkan bersama tiga orang pensyarah teknikal yang berpengalaman bagi menguatkan hasil dapatan. Hasil analisis tema terhadap perbincangan FGD telah berjaya menemui enam tema utama dan sepuluh sub tema. Tema utama ialah (1) Niat, (2) Azam, (3) Sabar, (4) Istiqamah, (5) Doa dan Tawakal, dan (6) Jaga Hubungan. Hasil kajian ini dapat dijadikan panduan untuk pelajar TVET dalam merangka kerjaya mereka berpandukan syariat Allah SWT.
\end{abstract}

Kata kunci: Perancangan kerjaya, teknikal, nilai kerohanian.

Abstract Career is an important agenda in Islam towards the concept of the world as a bridge to afterdeath. A good career needs to be planned to ensure that it is congruent, halal and meets the requirements of Islam even in a technical field that is full of practicals and manual labour. The application 
of spiritual values is a must in career planning to ensure that the planning meets the requirements of Islamic law. This is because without the element of spirituality, an individual is empty in terms of manners to be a good employee. Therefore, this study was conducted to explore the application of spiritual values in career planning required by Technical and Vocational Education Training (TVET) students to be a balanced workforce in terms of skills and manners. This qualitative study used Focus Group Discussion (FGD) as the data collection method. The study participants consisted of 12 graduates of community colleges and polytechnics who have been successful in their careers, combined with three experienced technical lecturers to strengthen the findings. The results of the thematic analysis of the FGD discussion have successfully found six main themes and ten subthemes. The main themes are (1) Intention, (2) Determination, (3) Patience, (4) Istiqamah, (5) Prayer and Trust, and (6) Keeping Relationships. The results of this study can be used as a guide for TVET students in planning their careers based on the law of Allah SWT.

Keywords: Career planning, technical, spiritual values.

\section{PENDAHULUAN}

Bekerja adalah tuntutan Islam ke atas semua penganutnya untuk menyara kehidupan kerana Islam sangat melarang perbuatan meminta-minta. Malah, firman Allah dalam Surah at-Taubah, ayat 105 yang bermaksud:

Dan katakanlah (wahai Muhammad); Bekerjalah kamu maka Allah dan Rasul-Nya serta orang-orang yang beriman akan melihat apa yang kamu kerjakan dan kamu akan dikembalikan kepada Allah yang mengetahui perkara-perkara yang ghaib dan yang nyata, kemudian ia menerangkan kepada kamu apa yang kamu telah kerjakan.

Islam memandang bekerja untuk dunia merupakan jambatan untuk berjaya di akhirat dan seharusnya umat Islam tidak boleh mengabaikan pekerjaan dunia mereka demi merebut ganjaran syurga. Tanpa kerjaya yang baik umat Islam akan menjadi hina dan dipandang rendah oleh bangsa lain. Malah, Allah dan Rasul-Nya menyuruh umat Islam mencari pekerjaan yang halal dan diredai supaya mereka boleh berjaya di dunia dan akhirat. Para 
ilmuwan dalam bidang kerjaya pula menyarankan supaya memilih kerjaya yang kongruen dengan personaliti dan minat bagi mendapatkan keselarasan kerjaya (Holland, 1973). Pencarian kerjaya yang halal, mulia dan kongruen ini sukar untuk berlaku secara semula jadi atau berkembang dengan sendiri. Super et al. (1996) menjelaskan kerjaya perlu dibimbing dan boleh dipercepatkan jika ada perancangan yang baik. Malah, kebanyakan teori kerjaya lain seperti Roe, Krumboltz, Holland dan lain-lain menyarankan perkembangan kerjaya semenjak awal perkembangan manusia lagi (Ahmad Rosli, 2016). Namun begitu, dalam perkembangan ilmu pada zaman moden ini ia didominasi oleh fahaman sekularisme sehingga memisahkan jauh antara ilmu dengan unsur spiritual agama. Sedangkan, Zohar dan Marshall (2000) menegaskan, kecerdasan spiritual ialah kecerdasan yang digunakan untuk menyelesaikan permasalahan makna dan nilai. Kemahiran ini membolehkan hidup seseorang menjadi lebih berdimensi, berjaya dan bermakna. Ia merupakan kecerdasan tertinggi yang perlu dimiliki oleh individu untuk kehidupan seharian mereka.

\section{PERMASALAHAN KAJIAN}

Perancangan kerjaya yang baik merupakan kunci kepada kejayaan untuk mendapatkan kerjaya cemerlang pada masa depan dan banyak kajian menunjukkan perancangan kerjaya sangat berpengaruh dalam menentukan hala tuju kerjaya masa depan individu. Kajian Yamao et al. (2013) di Jepun dan Owen et al. (2011) di Turki tentang kesan pendidikan kerjaya kepada pelajar teknikal membuktikan pelan perancangan kerjaya yang baik akan membantu pelajar untuk berjaya dalam kerjaya mereka selepas tamat pengajian. Malah, kajian Rasul et al. (2015) juga membuktikan perancangan kerjaya sangat diperlukan oleh pelajar TVET di Malaysia untuk mereka mencapai kematangan kerjaya. Mereka mendapati pendidikan kerjaya yang dihubungkan dengan situasi dan komunikasi sebenar sangat berkesan dalam membina pengetahuan kerjaya dalam kalangan pelajar.

Hasilnya, banyak perancangan kerjaya telah dihasilkan untuk individu seperti model bimbingan kerjaya RAISE, Program Eksplorasi Kerjaya (Work Experience/Career Exploration Program) WECEP dan program Career Academy dihasilkan berdasarkan perkembangan umur dan dengan 
pengkhususan kepada kumpulan 'remaja berisiko,' iaitu pelajar atau remaja yang berisiko untuk gagal dalam pembelajaran mereka atas sebab-sebab tertentu (Amla Mohd Salleh, 2010). Namun begitu, kebanyakan perancangan kerjaya bermodul dan teori-teori perancangan kerjaya ini datangnya daripada Barat yang mempunyai kekurangan daripada aspek spiritualiti. Para pelajar di Malaysia terutamanya di institusi TVET yang majoritinya adalah Muslim memerlukan sentuhan kerohanian dalam perancangan kerjaya mereka (Othman et al., 2020). Malah, Al-Ghazali et al. (2001) ada menyentuh peranan kerohanian dalam menjadikan sesuatu kerjaya sebagai ibadah yang akhirnya akan melahirkan pekerja yang cemerlang dan berdedikasi.

Menyedari tentang pentingnya nilai-nilai kerohanian sebagai pemangkin kepada kepada kejayaan individu dalam kerjaya, maka kajian ini telah dilaksanakan untuk meneroka aspek kerohanian dalam perspektif Islam sebagai panduan untuk para pelajar TVET dalam merancang kerjaya mereka.

\section{METODOLOGI KAJIAN}

\section{Reka Bentuk Kajian}

Kajian secara kualitatif ini akan menggunakan kaedah FGD bagi meneroka unsur kerohanian dalam perancangan kerjaya pelajar TVET. Morgan (2010) mendefinisikan FGD sebagai teknik kajian yang menggunakan interaksi kumpulan sebagai instrumen untuk mengutip data. Berg (2004) pula mendefinisikan FGD sebagai kaedah temu bual untuk kumpulan kecil. Ia adalah satu teknik kajian kualitatif dan dipanggil "Focus" kerana bentuk persoalan yang dikemukakan (Thornton \& Faisandier, 1998). Penggunaan FGD disarankan oleh Bloor et al. (2002) dan Barbour (2007) bagi menghasilkan dapatan kajian yang lebih tepat dan bermutu dalam kajian penerokaan sesuatu situasi atau mendalami sesuatu isu. Seramai 15 orang pakar rujuk yang terdiri daripada 12 orang alumni kolej komuniti dan politeknik yang telah berjaya dalam kerjaya bersama dengan tiga orang pensyarah kolej komuniti yang mempunyai pengalaman mengajar lebih daripada sepuluh tahun telah dilibatkan. Proses-proses FGD adalah seperti berikut: 
a. Peringkat Pertama FGD: Menetapkan tempat bersidang dan peraturan asas perbincangan

Kaedah perbincangan ini sangat efektif digunakan dalam kajian yang bersifat penerokaan kerana mampu mencungkil maklumat dengan maksimun. Namun begitu, FGD memerlukan persediaan yang baik bagi memastikan keberkesanannya dalam penerokaan fenomena yang ingin dikaji (Morgan, 2010). Dalam hal ini, moderator berperanan penting dalam kejayaan perbincangan dan perlu bijak memulakan perbincangan dengan formal, memperkenalkan semua peserta kajian, menetapkan matlamat perbincangan dan menyatakan maklumat latar belakang tujuan kajian. Mereka juga perlu memberi penekananan kepada kerahsiaan hasil perbincangan dan menerangkan bagaimana data-data yang diperoleh akan diteroka dan diproses untuk tujuan kajian ini.

\section{b. Peringkat Kedua FGD: Pengenalan individu}

Sebanyak tiga perkara perlu diambil kira dalam permulaan menjalankan FGD. Pertama, FGD merupakan satu metode yang khusus untuk kutipan data. Oleh itu, pengkaji perlu memastikan data dikutip semaksimum mungkin. Kedua, interaksi yang berlaku dalam FGD merupakan sumber data utama, justeru proses interaksi dalam FGD perlu interaktif dan setiap panel perlu membabitkan diri. Ketiga, pengkaji selaku moderator perlu memlibatkan diri secara aktif dalam FGD bagi memastikan aliran perbincangan berjalan dengan lancar dan tiada panel berasa terpinggir dalam perbincangan. Apabila semua maklumat personel telah diterangkan oleh setiap peserta, pengkaji boleh menyelitkan peraturan-peraturan asas perbincangan, faedah-faedah perbincangan dan mewujudkan perasaan kekitaan dalam kalangan peserta kajian.

\section{c. Peringkat Ketiga: Permulaan topik}

Setelah selesai pengenalan individu, pengkaji boleh memulakan perbincangan secara umum dengan memperkenalkan topik perbincangan. Kitzinger (2005) menegaskan ada dua bentuk interaksi dalam FGD, iaitu pertama (1) Maklumat pelengkap (perkongsian pengalaman, kebimbangan dan keperluan individu) dan kedua (2) Percanggahan maklumat (persoalan, perdebatan dan cabar-mencabar). Oleh itu, moderator perlu bijak untuk menangani jangkaan interaksi yang bakal timbul dalam FGD. Mereka 
mesti sentiasa aktif dan cuba menghidupkan suasana perbincangan dan menggalakkan semua orang bercakap dengan menggunakan teknik penyoalan yang baik. Semua responden digalakkan bercakap dan elakkan dominasi seorang atau dua orang individu sahaja dalam perbincangan. Hal ini akan menyebabkan perbincangan menjadi sehala dan hambar. Justeru, pada peringkat ini moderator perlu bijak menyusun ayat bagi menarik minat panel untuk memulakan perbincangan dan pergi lebih jauh ke dalam isu atau fenomena yang ingin dibincangkan.

\section{d. Peringkat Keempat: Perbincangan}

Pada masa ini, moderator perlu membuat penyoalan yang relevan dengan isu yang hendak dibincangkan. Ia perlu dijalankan dengan bijak tanpa mewujudkan rasa tidak selesa kepada panel-panel perbincangan (Stewart et al., 2007). Langkah ini akan membolehkan panel berasa selesa untuk bercakap dan berbincang tentang isu yang dibangkitkan. Apabila suasana selesa sudah dicipta, moderator perlu memastikan perbincangan berada pada landasan yang betul dan berada dalam kawalan. Soalan-soalan yang dikemukakan mestilah perlu berpandukan protokol perbincangan yang telah disediakan lebih awal dan moderator boleh membuat soalan susulan bagi merancakkan lagi perbincangan. Pada peringkat ini, ada kemungkinan pengkaji akan berasa hilang kawalan pada perbincangan, terutama jika keadaan perbincangan menjadi hangat dan tidak terkawal. Justeru, menjadi tugas pengkaji adalah menilai keadaan perbincangan dan mengawal keadaan agar perbincangan berlangsung dalam keadaan terkawal.

\section{e. Peringkat Kelima: Penutup perbincangan}

Topik terakhir yang hendak dibincangkan perlu disediakan terlebih dahulu oleh pengkaji. Penutup perbincangan dicadangkan agar dibuat dalam keadaan positif dan dihabiskan sepenuhnya agar tiada ralat (unfinished business) dalam kalangan peserta kajian. Moderator perlu memberi perhatian agar perbincangan dihabiskan mengikut masa yang telah ditetapkan di awal sesi dan perbincangan dikawal apabila masa hampir tamat dengan sentiasa memberi ingatan tentang kesuntukan masa perbincangan serta meminta kesimpulan pada setiap pendapat yang diberi (Liamputtong, 2012). Namun begitu, moderator perlu memberi ruang dan peluang untuk responden menghabiskan perkara atau isu yang ingin mereka sampaikan (Hennink, 
2007). Akhirnya, perbincangan ditamatkan dengan mengucapkan terima kasih kepada semua responden yang terlibat menerangkan dalam kajian ini. Setelah selesai, tutup pita rakaman dan berikan penghargaan kepada semua yang terbabit.

\section{Analisis Kajian}

Analisis tema telah dilakukan untuk mengenal pasti tema yang muncul (emergence) daripada FGD dengan melihat kepada interaksi dan dinamik sosial yang berlaku dalam kumpulan (Macnaughten \& Myers, 2004). Analisis ini membantu melihat paten yang boleh menunjukkan peserta mengetahui apa yang diperkatakan, hubungan antara moderator dan peserta, hubungan antara peserta dengan topik dan perbualan yang berlaku. Begitu juga dengan pengulangan penegasan, diam seketika sebelum meneruskan ayat dan lain-lain yang menghangatkan perbincangan dan menarik audiens untuk berbicara. Justeru, apabila menganalisis transkrip, pengkaji telah melihat kepada keseluruhan transkrip, mengimbau semula situasi yang berlaku dalam perbincangan dan mengkaji bentuk interaksi peserta perbincangan (Macnaughten \& Myers, 2004). Transkrip rakaman dapat membantu pengkaji menganalisis perbincangan di mana;

- $\quad$ semua ayat perlu ditranskripkan menggunakan bahasa biasa.

- $\quad$ Perkataan ulangan, ayat tidak lengkap atau tiada maksud seperti $u h$ $u h, m m$ dan seumpamanya tidak perlu dimasukkan.

- Frasa atau perenggan yang sukar difahami perlu diteliti dan dipastikan semula maksudnya,

- $\quad$ Tidak perlu menyatakan perbualan terhenti, ayat pintas, nada suara tinggi atau rendah, bentuk intonasi melainkan pada penekanan konvensional.

Langkah-langkah ini bagi memudahkan proses transkripsi dan menjadikannya mudah dibaca dan difahami. Ciri lain yang boleh dimasukkan selagi tidak mengganggu tumpuan pembaca atau mempengaruhi tanggapan pembaca. Proses transkrip bukan berkisar pada persoalan memilih dan atau tidak dipilih tetapi antara pilihan untuk lain-lain tujuan. Liamputtong (2012) mengingatkan tujuan utama FGD adalah lebih kepada menjana idea dan 
bukannya mencari persetujuan bersama untuk setiap isu yang dibincangkan. Begitupun, persetujuan bersama panel FGD akan memudahkan pengkaji menilai sesuatu perkara atau isu.

Dalam kajian ini, analisis FGD adalah untuk menghasilkan kerangka laluan perkembangan kerjaya dan pada masa yang sama untuk menghasilkan idea-idea tambahan serta melihat pelaksanaan kerangka laluan perkembangan kerjaya dalam realitinya di kolej komuniti. Seperti juga dengan temu bual Teknik Delphi, analisis untuk FGD juga menggunakan kod bagi mewakili panel FGD. Contoh sistem kod yang digunakan oleh pengkaji untuk mengekodkan data FGD adalah seperti FG-KA-USH. Kod FG merujuk kepada proses FGD, kod KA mewakili nama responden dan kod USH pula mewakili pekerjaan responden yang ditemu bual iaitu usahawan [FG-KA-USH]. Seterusnya, bagi kod dan ungkapan ayat daripada mereka telah dijadikan sandaran untuk menerima atau menolak faktor kritikal yang menjadi asas kepada kerangka laluan perkembangan kerjaya pelajar kolej komuniti. Ia akan disokong oleh bentuk interaksi panel seperti meyokong, membangkang, sinis atau kurang senang yang dipamerkan dalam diskusi ini.

\section{DAPATAN DAN PERBINCANGAN}

Apabila membicarakan tentang pekerjaan bagi orang Islam, maka kita tidak boleh lari untuk membicarakan tentang aspek kerohanian yang menjadi tunjang kepada kehidupan orang Islam. Hal ini demikian kerana, Islam memandang kerjaya sebagai satu kepentingan material atau kebendaan yang diperlukan demi kelangsungan kehidupan manusia di muka bumi ini (Sidek, 2006). Takrifan pemantapan kerohanian dalam kajian ini merujuk kepada aspek dalaman yang berkait rapat dengan aspek iman, akhlak dan adab seorang Muslim. Ia merangkumi niat yang baik dan keazaman yang kuat.

\section{Niat}

Niat merupakan satu perkara yang paling penting dalam melaksanakan sesuatu pekerjaan atau perbuatan. Bagi individu Muslim, apabila melakukan pekerjaan mestilah memulakan pekerjaan itu dengan niat yang ikhlas kerana Allah SWT bagi menjadikan pekerjaan tersebut satu ibadah kepada 
Allah SWT dan mendapat pahala bagi yang melakukannya. Justeru, Islam menyarankan bahawa setiap individu Muslim yang melaksanakan pekerjaan perlu mempunyai niat yang baik bagi memastikan pekerjaan yang dilakukan mendatangkan manfaat kepada diri sendiri dan orang lain.

Panel FG-PN-PL meletakkan subtema niat sebagai asas kepada kejayaan pelajar. Beliau berpendapat setiap individu yang memulakan kerja atau pengajian perlu memulakannya dengan niat yang baik. Ia akan menjadikan seseorang itu sabar, mempunyai keazaman dan mampu beristiqamah. Ia disokong oleh panel FG-PM-PL, FG-PF-PL dan FG-PKPL yang menegaskan keperluan untuk memasang niat bagi memastikan keberterusan usaha yang dijalankan dan mampu bersabar dengan dugaan yang datang. Jadual 1 menunjukkan ringkasan subtema niat dan kod yang terkandung di dalamnya.

Jadual 1 Ringkasan dapatan data temu bual subtema niat

\begin{tabular}{ll}
\hline Berkaitan Kod & Petikan Temu Bual \\
\hline Niat yang ikhlas & "Pada saya niat ikhlas ini adalah seumpama letakkan \\
& matlamat untuk dicapai... ia jadikan kita berani untuk \\
bersaing... sabar dan mampu untuk terus bertahan dalam & menghadapi cabaran". \\
& FG-PN-PL \\
& \\
Niat yang baik & Seorang golongan bumiputera Islam, orang muda... kita nak \\
& bangunkan ekonomi ummah kita". \\
& FG-JK-USH \\
\hline
\end{tabular}

Menurut peserta kajian, niat yang ikhlas dalam melakukan pekerjaan merupakan pembuka jalan dalam membangunkan kerjaya mereka. Hal ini demikian kerana, niat yang ikhlas akan membolehkan mereka menumpukan fokus untuk bekerja kerana Allah dan bukan untuk mendapatkan ganjaran keduniaan semata-mata. Sementara itu, tujuh orang responden menegaskan niat yang baik perlu ada pada setiap individu dalam berkerjaya. Hal ini disebabkan setiap pekerjaan perlu memberi manfaat, bukan sahaja kepada diri sendiri tetapi juga kepada Allah. 


\section{Azam}

Islam menyarankan bahawa setiap individu yang melaksanakan sesuatu pekerjaan perlu mempunyai azam iaitu motivasi dan kemahuan yang kuat untuk berusaha dan bekerja secara bersungguh-sungguh (Sidek, 2006). Dalam kajian ini, azam merujuk kepada keinginan yang diiringi dengan usaha bersungguh-sungguh individu untuk mencapai kejayaan dalam bidang kerjaya yang diceburi. Dua kod telah dikenal pasti dalam subtema ini, iaitu keazaman yang kuat dan berani berazam. Keazaman yang kuat merujuk kepada kemahuan yang besar dalam diri untuk berjaya dalam kerjaya masa depan. Berani berazam pula merujuk kepada kekuatan dalaman seseorang untuk berazam mencapai cita-cita yang pada mulanya kelihatan mustahil untuk dicapai oleh pelajar kolej komuniti.

Seramai lima orang responden menegaskan keazaman yang kuat amat diperlukan jika ingin berjaya dalam kerjaya, terutama bagi mereka yang berkecimpung dalam bidang perniagaan. Hal ini demikian kerana, cabaran-cabaran yang mendatang dan rintangan yang bakal dilalui sangat mencabar untuk diharungi. Tanpa keazaman yang tinggi mereka akan hanyut dan berputus asa untuk meneruskan kerjaya mereka, manakala dua orang responden mengatakan kekuatan mereka terletak kepada keberanian mereka untuk berazam. Hal ini disebabkan kebanyakan pelajar kolej komuniti mempunyai keyakinan diri yang rendah dan tidak berani menzahirkan keazaman mereka untuk berjaya dalam kerjaya masa depan. Kebanyakannya menganggap mereka sukar untuk berjaya dan bagi mereka yang berani untuk berazam, ia memberikan kekuatan kepada mereka untuk mencapai cita-cita yang dirancang. Jadual 2 menjelaskan dapatan tema dan subtema ini dalam perancangan kerjaya. 
Jadual 2 Ringkasan dapatan data temu bual subtema azam

\begin{tabular}{ll}
\hline Berkaitan Kod & Petikan Temu Bual \\
\hline Keazaman yang kuat & "Azam dan tekad kena kuat la... mental dan fizikal kena \\
& kuat... keyakinan kepada diri mesti ada... tak boleh down \\
& kalau orang cakap apa-apa... lebih-lebih lagi bisnes macam \\
& saya ni banyak dimonopoli oleh orang Cina". \\
& FG-BS-USH \\
& "Saya tak ada apa-apa yang istimewa... saya cuma ada \\
& berani sahaja... berani untuk berazam... berani untuk buat \\
Berani berazam & FGang saya rancang" \\
&
\end{tabular}

\section{Sabar}

Sabar diertikan sebagai kuat menahan penderitaan seperti kesakitan, kesusahan dan sebagainya (Muhammad Isa, 2000). Sabar dalam kajian ini merujuk kepada ketahanan individu menempuh cabaran pekerjaan dalam usahanya memajukan kerjaya yang diceburi. 1 kod telah dikenal pasti dalam subtema ini, iaitu kesabaran yang tinggi seperti yang terkandung dalam Jadual 3.

Jadual 3 Ringkasan dapatan data temu bual subtema sabar

\begin{tabular}{ll}
\hline Berkaitan Kod & Petikan Temu Bual \\
\hline Kesabaran yang tinggi & "Banyak juga pelanggan saya yang tak yakin saya boleh \\
& buat... kadang-kadang kalau silap sikit kena marah... semua \\
& tu kena sabar la... jangan cepat marah, kalau tak, nanti \\
& pelanggan lari". \\
& FG-KT-PK \\
& "Saya punya kerja... memang banyak kena jumpa agensi- \\
& agensi ini... swasta cari saya untuk kelulusan... saya pun \\
& kena ikut banyak prosedur... memang kena sabar la... kalau \\
& tak... tak jadi kerja". \\
& FG-KA-USH \\
\hline
\end{tabular}

Kesabaran yang tinggi memang sangat kritikal bagi menjamin keberterusan usaha memajukan kerjaya dan ia telah dipersetujui oleh empat responden yang menjadikan sifat terpuji ini sebagai amalan mereka. Bagi FG-KT-PK, posisi jawatannya yang berkaitan dengan kontrak dan kewangan menyebabkan beliau sentiasa mendapat tekanan daripada pihak atasan atau 
swasta. Justeru, kesabaran yang tinggi amat diperlukan bagi memastikan tanggungjawab yang dipikul mampu dilaksanakan dengan baik. Begitu juga dengan FG-KA-USH yang berhadapan dengan pelbagai kerenah pelanggan. Namun, beliau menyatakan sifat sabar merupakan kunci untuk beliau menambat hati para pelanggan dan meyakinkan mereka setiap tempahan yang dibuat akan memuaskan hati. Hal ini bertepatan dengan firman Allah dalam Surah al-Imran ayat 146 yang bermaksud, "Dan Allah mencintai orang-orang yang sabar".

\section{Istiqamah}

Istiqamah bermaksud amalan dan ketekunan yang berterusan dalam sesuatu urusan. Bagi kajian ini, ia merujuk kepada konsistensi seseorang dalam kerjaya yang diceburi dan kemampuannya untuk terus berada dalam dunia kerjaya yang berkenaan seperti yang ditunjukkan dalam Jadual 4 .

Jadual 4 Ringkasan dapatan data temu bual subtema istiqamah

\begin{tabular}{ll}
\hline Berkaitan Kod & Petikan Temu Bual \\
\hline Istiqamah & "kalau kita ada minat kena teruskan... jangan ikut orang... \\
dalam kerjaya & lepas tu tak jalan... kalau buat... kena buat sampai habis \\
& kerja tu". \\
& FG-IK-PK \\
& "Kita perlu ada semangat dalam diri tu... kita buat untuk \\
& masa depan kita... saya rasa dengan semangat yang kuat \\
& kita boleh berjaya". \\
& FG-KA-US \\
\hline
\end{tabular}

Bagi enam orang panel kajian, mereka merasakan tanpa istiqamah segala usaha akan terbantut. Hal ini disebabkan cabaran-cabaran yang wujud dalam berkerjaya mampu meranapkan usaha-usaha yang telah digiatkan sebelum ini dan menimbulkan rasa putus asa pada mereka. Ia disokong oleh panel FG-PM-PL, FG-PF-PL dan FG-PK-PL yang menegaskan keperluan untuk istiqamah bagi memastikan keberterusan usaha yang dijalankan dan mampu bersabar dengan dugaan. 


\section{Doa dan Tawakal}

Doa dan tawakal adalah senjata terakhir orang mukmin setelah mereka berusaha bersungguh-sungguh. Doa adalah permintaan daripada hamba kepada Tuhannya untuk mendapatkan sesuatu, manakala tawakal adalah berserah diri kepada Allah untuk menentukan pengakhirannya sama ada baik atau buruk. Gabungan doa dan tawakal menjadi azimat kepada individu untuk berjaya setelah berusaha dan mampu menjadi pengubat kekecewaan jika usaha itu gagal membuahkan hasil. Dua kod dalam subtema ini adalah berdoa kepada Allah dan berserah diri seperti yang dipaparkan dalam Jadual 5.

Tawakal menurut Al-Ghazali et al. (2001) ialah hati yang teguh bergantung harap pada Allah dan sentiasa rasa tenang dengan-Nya. Kita percaya bahawa dalam apa jua yang Allah takdirkan sentiasa ada hikmah yang terkandung di sebaliknya. Seseorang yang bertawakal mampu melahirkan jiwa yang teguh asbab keyakinannya bahawa Allah akan sentiasa ada dan memberi hidayah dalam pelbagai cara. Ia akan menjadikan individu tersebut mempunyai sifat daya tahan yang tinggi dalam menghadapi cabaran kerjayanya (Suriani Sudi et al., 2019).

Dua panel menegaskan mereka pernah gagal dan pada ketika itu hanya doa yang menjadi penawar dan pengubat kekecewaan mereka. Begitu juga apabila berhadapan dengan sesuatu permasalahan atau cabaran, mereka akan berusaha dan kemudiannya bertawakal kepada Allah kesudahannya sama ada berjaya atau gagal. Ia adalah cara berusaha yang dianjurkan oleh Islam, malah agama-agama lain juga menggalakkan penganutnya untuk berdoa kepada Tuhan mereka untuk mendapatkan sesuatu. 
Jadual 5 Ringkasan dapatan data temu bual sub tema doa dan tawakal

\begin{tabular}{|c|c|}
\hline Berkaitan Kod & Petikan Temu Bual \\
\hline Berdoa kepada Allah & $\begin{array}{l}\text { "Dulu... saya buat kuih tak jadi... sebulan saya tak dapat } \\
\text { keluarkan apa-apa... saya berdoa pada Allah...tolong } \\
\text { saya... lepas tu saya usaha macam-macam, akhirnya Allah } \\
\text { tunjukkan cara". } \\
\text { FG-DA-USH }\end{array}$ \\
\hline Berserah diri & $\begin{array}{l}\text { "Saya tak pernah jemu minta tender kerajaan... walaupun } \\
\text { tahu orang kata kena ada kabel... tapi dalam diri saya... kalau } \\
\text { Tuhan nak bagi... Dia akan bagi". FG-BD-USH }\end{array}$ \\
\hline
\end{tabular}

\section{Jaga Hubungan}

Hubungan bermaksud sambungan atau rangkaian sama ada persaudaraan, persahabatan dan sebagainya (DBP, 2021). Dalam kajian ini jaga hubungan diertikan sebagai memelihara ikatan yang wujud antara individu dengan penciptanya dan perhubungan sesama manusia. Dua kod utama dalam subtema ini ialah perhubungan dengan Allah/Tuhan dan perhubungan dengan manusia yang signifikan dalam hidupnya seperti ibu bapa, pensyarah, rakan dan sebagainya. Hubungan individu dengan Allah/Tuhan adalah perkara terpenting dalam kehidupan manusia di dunia. Begitu juga hubungan dengan sesama manusia kerana ia merupakan faktor penting dalam menyumbang kejayaan seseorang manusia. Hal ini demikian kerana, tanpa reda Allah, maka hancurlah kehidupan manusia di dunia dan tiada jaminan keselamatan untuknya di akhirat. Perhubungan sesama manusia pula sangat penting kerana sebagai umat manusia yang bertamadun adalah mustahil untuk seseorang itu hidup tanpa sesiapa pun di sisinya (Sayid Anshar, 2019). Tiada manusia yang mampu mengusahakan kejayaan dengan berseorangan diri dalam dunia globalisasi sekarang ini.

Panel FG-PM-PL menegaskan doa dan tawakal sebagai senjata terakhir terutama ketika berdepan dengan masalah. Bagi mereka, dua elemen ini adalah jalan keluar terbaik setelah berusaha bersungguh-sungguh untuk mencapai kejayaan. Ia disokong oleh panel FG-PJ-PS dan panel FG-PK-PL yang sentiasa menjadikan doa dan tawakal sebagai perangsang kejayaan. Mereka menegaskan, kemampuan manusia adalah terbatas dan ada kalanya kita perlu menyerahkan keputusan kepada Tuhan untuk menentukan. 
Jadual 6 menunjukkan majoriti responden menekankan kepentingan menjaga hubungan baik dari segi perhubungan dengan Allah mahupun perhubungan sesama manusia. Hal ini demikian kerana mereka merasakan amalan ini adalah satu kekuatan kepada mereka dalam menjalankan aktiviti seharian. Ia juga menjadi jalan untuk melepaskan diri daripada tekanan dan permasalahan. Ia seiring dengan tuntutan Islam yang sentiasa menekankan kepentingan habluminallah dan habluminnas (hubungan dengan Allah dan manusia) dalam mendapat kebahagiaan di dunia dan akhirat.

Jadual 6 Ringkasan dapatan data temu bual subtema jaga hubungan

\begin{tabular}{|c|c|}
\hline Berkaitan Kod & Petikan Temu Bual \\
\hline Hubungan dengan Allah & $\begin{array}{l}\text { "Rezeki kan... ada kala baik, ada kala buruk...kita dah } \\
\text { usaha, lepas tu doalah... serah pada Allah la." } \\
\text { FG-PM-PL }\end{array}$ \\
\hline $\begin{array}{l}\text { Hubungan dengan } \\
\text { manusia }\end{array}$ & $\begin{array}{l}\text { "Faktor luaran di sebalik kejayaan saya kebanyakannya } \\
\text { dorongan kawan-kawan dan dengan keluarga... penting tu } \\
\text { restu keluarga." } \\
\text { FG-JH-PK }\end{array}$ \\
\hline
\end{tabular}

\section{KESIMPULAN}

Kajian ini telah berjaya untuk mencapai objektifnya bagi meneroka penerapan nilai kerohanian dalam perancangan kerjaya untuk pelajar TVET. Sebanyak enam tema utama telah berjaya dicungkil bersama dengan sepuluh subtema. Hasil FGD menunjukkan ketika merancang kerjaya setiap pelajar perlu mempunyai niat, azam, sabar, istiqamah, doa, dan tawakal dan jaga hubungan. Elemen tersebut saling melengkapi di antara satu sama lain dan kesemua elemen ini telah dipraktikkan oleh lulusan TVET yang telah berjaya sebelum ini. Ia amat signifikan kerana kebanyakan mereka mempunyai latar belakang akademik yang sederhana semasa dalam pengajian mereka namun masih mampu berjaya dalam kerjaya.

Elemen ini amat sesuai untuk dipraktikkan oleh para pelajar TVET, terutama pelajar Muslim kerana kerohanian merupakan senjata orang mukmin dalam menghadapi dunia kerjaya yang mencabar. Pelajar TVET Muslim seharusnya dapat membezakan perkara yang baik dan buruk jika 
berpegang kepada ajaran agama. Ia menepati semangat Falsafah Sejahtera dan Falsafah Pendidikan Kebangsaan yang menekankan kepada insan yang seimbang dari segi jasmani, emosi, rohani dan intelek. Usaha ini bertujuan melahirkan rakyat Malaysia yang berilmu pengetahuan, berketerampilan, berakhlak mulia, bertanggungjawab dan berkeupayaan mencapai kesejahteraan diri, serta memberi sumbangan terhadap keharmonian dan kemakmuran keluarga, masyarakat dan negara.

\section{RUJUKAN}

Ahmad Rosli Mohd Nor. (2016). Profil, indikator, faktor kritikal dan model perkembangan kerjaya berasaskan komuniti berpendap atan tinggi dalam kalangan lulusan kolej komuniti. Tesis Ph. D (tidak diterbitkan). Fakulti Pendidikan, Universiti Kebangsaan Malaysia, Bangi.

Al-Ghazali, Abu Hamid \& Muhammad Ahmad. (2000). Ihya'Ulum al-Din. Kaherah: Dar al Taqwa li al-Thurath.

Amla Mohd Salleh. (2010). Pendidikan kerjaya dan pembangunan modal insan. Bangi: Penerbit UKM.

Barbour, R. (2007). Doing focus group. London. Sage Publications.

Berg, B.L. (2004). Qualitative research methods for the social sciences (8th ed.). London: Pearson.

Bloor, M., Frankland, J., Thomas, M. \& Robson, K. (2002). Focus group in social research. London: Sage Publication.

DBP. (2021). Kamus On-line. https://prpm.dbp.gov.my/cari1?keyword=kamus\%20 online.

Hennink, M. M. (2007). International focus group research: A handbook for the health and social science. Cambridge: Cambridge University Press.

Holland, J. L. (1973). Making vocational choice: A theory of careers. New Jersey: Prentice-Hall.

Kitzinger, J. (2005). Focus group research: Using group dynamics to explore perceptions, experiences and understandings. Dlm. I. Holloway (ed.), Qualitative Research in Health Care. Maidenhead: Open University Press.

Liamputtong, P. (2012). Focus group methodology: Principles and practice. London: Sage Publications.

Macnaughten, P., \& Myers, G. (2004). Focus group. Dlm. Seale, C., Gobo, G., Gubrium, J.F. \& Silverman, D. (eds.), Qualitative Research Practice. London: Sage Publications.

Morgan, D. L. (2010). Reconsideration the role of interaction in analysing and reporting focus groups. Qualitative Health Research, 20 (5), 718-722.

Muhammad Isa Selamat. (2000). Panduan memperoleh rahmat. Kuala Lumpur: Darul Nu'man. 
Othman, Z., Mohd Nor, A. R., \& Nik Ahmad, N. M. (2020). Faktor-faktor yang signifikan dalam perancangan kerjaya lulusan kolej komuniti. Politeknik \& Kolej Komuniti Journal of Life Long Learning, 4 (1), 1-10.

Rasul, M. S., Nor, A. R. M., \& Amat, S. (2015). Exploring critical factors of self concept among high income community college graduates. International Education Studies, 8(12), 43-55.

Sayid Anshar. (2019). Konsep negara hukum dalam perspektif hukum Islam. Soumatera Law Review, 2 (2), 235-245.

Stewart, D. W., Shamdasani, P. M., \& Rook, D. W. (2007). Focus group: Theory and practice (2nd ed.). Sage: Thousand Oaks, CA.

Super, D. E., Savickas, M. L., \& Super, C. M. (1996). The life-span, life-space approach to careers. Dlm Brown, D., Brooks, L., \& Associates (eds.), Career Choice and Development. San Francisco: Jossey-Bass.

Suriani Sudi, Fariza Md Sham, \& Phayilah Yama. (2019). Tawakal sebagai elemen kecerdasan spiritual menurut perspektif Hadis. Jurnal Pengajian Islam, 12(2), 157-167.

Yamao, H., Moriyama, J., Shimada, K., Ichihara, Y., Miyagawa, Y., Nakahara, H., \& Uenosono, T. (2013). Effects of career guidance on promoting students' job self-efficacy in technical high school: A longitudinal case study in Japan. Proceeding of Malaysia International Technical HRD \& 9th AASVET Conference, 168-176.

Zohar, D., \& Marshall, I. (2000). SQ (Spritual Intelligence): The Ultimate Intelligence. AJM January 2001. http://www.alisonmorgan.co.uk/Zohar.htm

MANU

Jurnal Pusat Penataran Ilmu \& Bahasa

(Journal of the Centre for the Promotion of Knowledge \& Language Learning) 
AHMAD ROSLI MOHD NOR (Ph.D) ialah Pensyarah Kanan di Akademi Pengajian Islam Kontemporari (ACIS), Universiti Teknologi MARA (UiTM) Cawangan Melaka. Beliau berkelulusan Ijazah Sarjana Muda Pengajian Islam (Pengajian Arab dan Tamadun) dari Universiti Kebangsaan Malaysia (UKM). Seterusnya, beliau melanjutkan pelajaran ke peringkat Ijazah Sarjana Pendidikan dalam bidang Bimbingan dan Kaunseling serta Ijazah Doktor Falsafah dalam bidang Kurikulum dan Pedagogi di Fakulti Pendidikan, UKM. Beliau juga merupakan Kaunselor Berdaftar dengan Lembaga Kaunselor Malaysia. Bidang pengkhususan beliau ialah Kaunseling, Kurikulum dan Tamadun Islam.

MOHAMMAD FAHMI ABDUL HAMID (Ph.D) ialah Pensyarah Kanan di Akademi Pengajian Islam Kontemporari (ACIS), Universiti Teknologi MARA (UiTM) Cawangan Melaka Kampus Alor Gajah. Beliau mendapat pendidikan awal di Institut Tahfiz al-Quran Negeri Sembilan. Kemudian, beliau melanjutkan pengajian di peringkat Ijazah Sarjana Muda di Universiti Putra Malaysia (UPM) pada tahun 2012. Beliau memperoleh Ijazah Sarjana Usuluddin (Hadis) pada tahun 2015 dan Ijazah Doktor Falsafah (Hadis) dari Akademi Pengajian Islam, Universiti Malaya (UM), Kuala Lumpur pada tahun 2019. Pengkhususan pengajian beliau adalah dalam bidang hadis dan beliau juga sangat meminati serta cenderung terhadap pengkajian dalam bidang tarekat dan tasawuf.

KHAIRUL AIZAL BIN OSMAN ialah Pensyarah Kanan merangkap Ketua Unit Pengajian Am di Kolej Komuniti Masjid Tanah, Kementerian Pengajian Tinggi. Beliau berkelulusan Bacelor Pendidikan (Bimbingan dan Kaunseling) dari Universiti Putra Malaysia (UPM) pada tahun 2003. Beliau telah menyambung pelajaran ke Universiti Kebangsaan Malaysia (UKM) pada tahun 2009 dan memperoleh Sarjana Sains Sosial (Psikologi Kaunseling) pada tahun 2011. Beliau juga merupakan Kaunselor Berdaftar dengan Lembaga Kaunseling Malaysia dan pengkhususan beliau adalah dalam Bimbingan dan Kaunseling. 